\title{
New and Probable Ultrastructural Criteria for Identification of Cytoplasmic Sol-Gel States
}

\author{
Nuevo y Probable Criterio Ultraestructural para la Identificación \\ de los Estados Citoplasmáticos Sol - Gel
}

Wiphawi Hipkaeo* \& Hisatake Kondo*

HIPKAEO, W. \& KONDO, H. New and probable ultrastructural criteria for identification of cytoplasmic sol- and gel-states. Int. J. Morphol., 34(1):212-217, 2016.

SUMMARY: In embedment-free transmission electron microscopy without employing epoxy embedding media, the cytoplasmic matrix, in which cell organelles and elements including the cytoskeletons are held in place, lattices of strands are clearly and constantly disclosed in every cell. Their compactness is variable in different kinds of cells and in different domains of one and the same cell, and it is changeable under hypo- or hyper-osmolarity. In addition, the appearance of strand-lattices is duplicable in artificial proteins at different sol/gel states and concentrations. All taken together, a new and probable ultrastructural criteria has been proposed for identification of cytoplasmic sol/gel states with a hope that the dynamic properties of the cell is understood not only by the cytoskeleton but also by the $\mathrm{sol} / \mathrm{gel}$ states of cytosolic proteins and their concentration in distinct association with cellular ultrastructural entities.

KEY WORDS: Sol and gel; Cytoplasm; Embedment-free; Ultrastructure.

\section{INTRODUCTION}

The gel is defined in physics as a tangled network of crosslinked molecules immersed in a liquid medium (Tanaka, 1981). The properties of the gel depend strongly on the interaction of the liquid and the molecule network. The former prevents the polymer network from collapsing into a compact mass, while the latter prevents the liquid from flowing away. The natures of gels in physics and chemistry including the swollen gel equilibrium have been fully described (Flory, 1953; Kuhn et al., 1955; Tanaka). On the other hand, the definition of biological gels is largely phenomenonical, and it has long been recognized that the cytoplasm is a living gel since late 19 th century (Crick \& Hughes, 1950; Landau et al., 1954; Chambers \& Chambers, 1961; Porter, 1984; Lechene, 1985). Thus, as represented by the amoeboid movement in conventional light microscopy, it was common to consider that the predominant explanation of the cell dynamics and intracellular movement involves the transition between the sol/gel states of intracellular soluble proteins occupying the cytoplasm (Buchsbaum et al., 1987; Taylor \& Condeelis, 1979; Pollack, 2001).

In conventional transmission electron microscopy (TEM) using epoxy embedding media, owing to its much higher resolution than light microscopy, various cell organelles and elements have been identified in cells in which a limited number of substructures were visible in light microscopy. As a result, the remaining cytoplasmic domains other than those occupied by the cell organelles and elements are termed the cytoplasmic matrix which is generally assumed to be sites of intracellular soluble proteins defined in biochemistry. Among the ultrastructural elements, the identification of cytoskeletal elements composed of microfilaments, intermediate filaments and microtubules, have contributed much to our understanding of the cell dynamics and intracellular movement in a way simply mimicked by cargos moving on rails without consideration of a wide variety of cytosolic proteins in the cytoplasmic matrix. Although the significance of the cytoskeleton in the intracellular movement is well accepted, there are no reasons to neglect the influence of massive cytosolic proteins intimately surrounding the cell organelles and ultrastructural elements in the intracellular movement probably through the transition of their sol/gel states. In order to clarify the influence of the transition of sol/gel states of cytosolic proteins on the intracellular movement, it is critical to observe the cytosolic proteins at sol/gel states as distinct morphological entities in ultrastructural relation to various cellular organelles and elements in TEM. 
However, since the clear visibility of targets in conventional TEM is owing to lipids, but not proteins, in their chemical compositions, the cytosolic proteins and their comprised cytoplasmic matrix do not acquire the electron density sufficient to overcome the intrinsic electron-density of embedding epoxy resin, resulting in their indistinct or just flocculent appearance in conventional TEM. Therefore, it is impossible to estimate the sol/gel states of proteins as well as their concentration in the cytoplasmic matrix in association with the cellular ultrastructural entities in conventional TEM. Thus, only phenomenological consideration of cytoplasmic sol/gel states without any association with the ultrastructural information has so far failed to attract much attention except for actin and its gelation factors. This difficulty in consideration of the cytoplasmic gels results in little progress in, or even neglect of, understanding about the biological significance in the intracellular dynamics of the sol/gel states of cytosolic proteins as well as their concentration as compared with the situation before development of TEM in biomedical fields. This is a rather irony, that is, the pursuit for observation at higher resolution in cytology results in the full discard of the afore-dominant understanding of the mechanisms on the intracellular dynamics.
Necessity and Development of Embedment-free section TEM. In order for the difficulty above to be resolved, it is critical to make ultrathin sections be free of epoxy embedment. Such an embedment-free TEM with a high quality was first introduced by the late KR Porter and his associates by using the critical point-drying after conventional chemical fixation of whole mount-cultured cells and observation in high voltage-TEM without the uranyl and lead staining (Wolosewick \& Porter, 1979; Porter). This was the first and sole method that disclosed clearly a distinct structural entity, that is, the strand-lattice originally termed microtrabecula, filling the cytoplasmic matrix. The strands range between $20-30 \mathrm{~nm}$ and $100-200$ $\mathrm{nm}$ in length, and between $2-3 \mathrm{~nm}$ and more than $10 \mathrm{~nm}$ in thickness. The ubiquitous occurrence in any tissue-cells of the strand-lattices was confirmed by an equivalent method in which fixed specimens was transiently embedded in polyethylene glycol (PEG), sectioned on a dry glass- or diamond-knife, de-embedded by dipping in water of sections on formvar-coated grids, and critical point-dried. This method is named as embedment-free section TEM (Wolosewick, 1980; Kondo et al., 1982). By careful observation of various tissue-cells in the embedment-free section TEM and by comparison of the findings with those
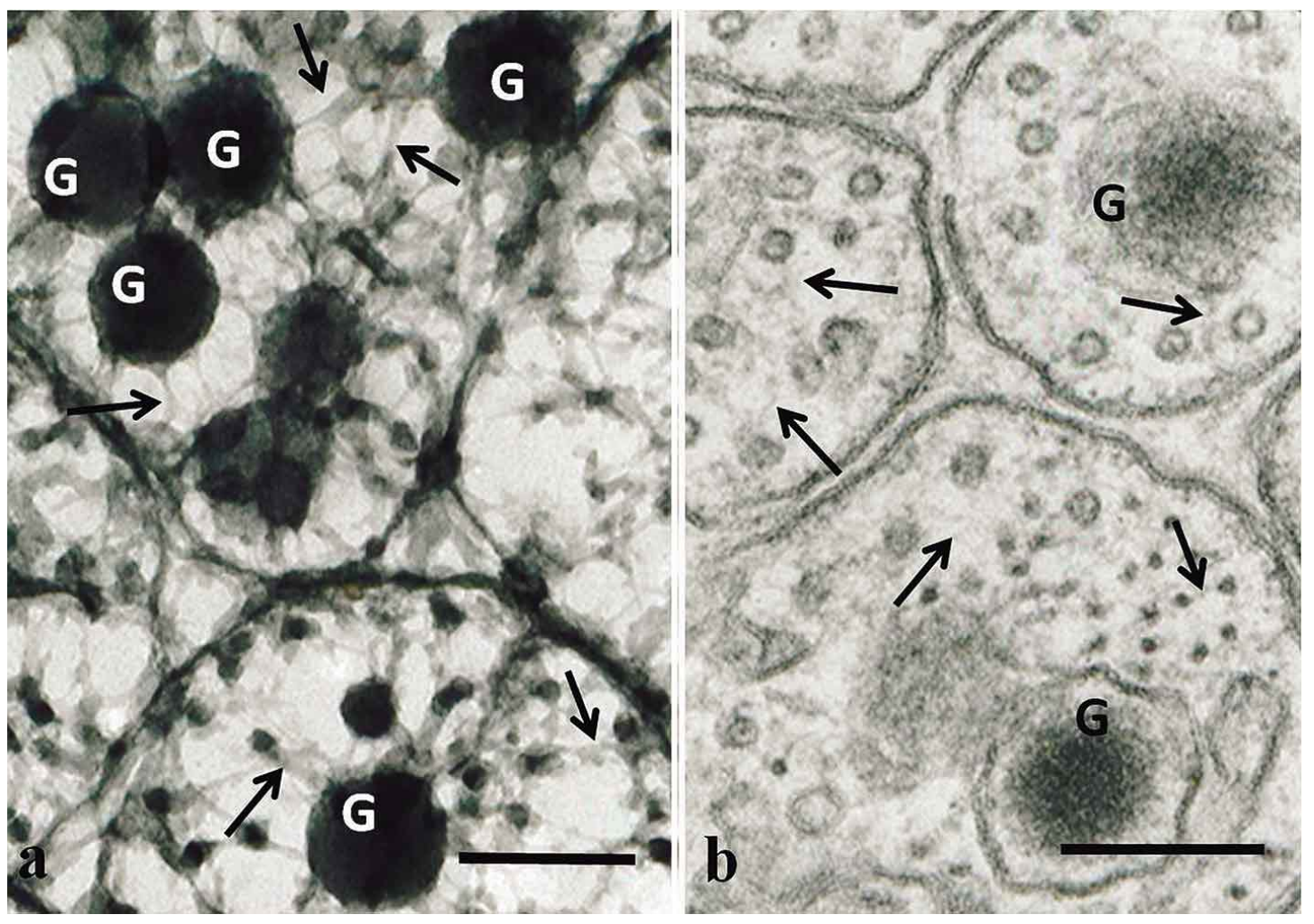

Fig. 1. Ultrastructures of neuronal axons of mice in embedment-free section TEM (a) and conventional epoxy TEM (b). Note distinct appearance of lattice-strands (arrows) in embedment-free section TEM in contrast to their indistinct (just flocculent) appearance in corresponding sites in conventional epoxy TEM in the cytoplasmic matrix among neurofilaments, neurotubules, vesicles and granules (G). Bars represent $200 \mathrm{~nm}$. 
in conventional TEM as well as those in freeze-etching replica TEM by others, the present author (Kondo, 1984a, $1984 b, 2006,2008)$ has clarified that the cell ultrastructures in the embedment-free section TEM are well-correlated to those in conventional TEM (Fig. 1). He has also made it clear that the strand-lattices are entities which are also present, but simply invisible in sectioned specimens in conventional TEM because of being masked by epoxy embedding media having a substantial electron density. All taken together, it is evident that the embedment-free TEM is methodologically reliable to observe biological specimens.

Consideration of cytoplasmic /cytosolic proteins in ultrastructure. Further observations of various tissue cells in this method have lead to notice that the cytoplasmic matrix disclosing more compact strand-lattices in the embedmentfree section TEM faithfully correspond to that exhibiting higher electron density in conventional TEM (Figs. 2a and 2b; please also refer to Figs. 5 \& 6 in Kondo, 2006; Figs. 16-19, 27, 28 in Kondo, 2008).
By in vitro expriments of artificial protein solutions in the embedment-free section TEM, strand-lattices similar to the cytoplasmic ones are duplicated in bovine serum albumin and solated gelatin fixed at warm temperature, at certain concentrations. The compactness of strand-lattices increases in proportion to the concentration of the protein solutions (Fig. 3). In contrast, strand-lattices from gelatin gelated by cooling before and during fixation are much more compact than those from solated gelatin at a given concentration (Fig. 4). This is the first clear demonstration of gels as forms of strands-lattices with the compactnesses dependent on the concentrations in TEM although a similar network feature of non-biological gels was briefly demonstrated in scanning EM, another embedment-free EM (Tohyama \& Miller, 1981). Furthermore, the compactness of strand-lattices in a give cell is changeable by brief incubation in a hypertonic or hypotonic medium, and the change was well compatible with the concentrationdependent change in the compactness of strand-lattices of BSA solutions in vitro (please refer to Figs. $42 \& 43$ in Kondo, 2008; Figs. 9a-9d in Kondo, 2015). a

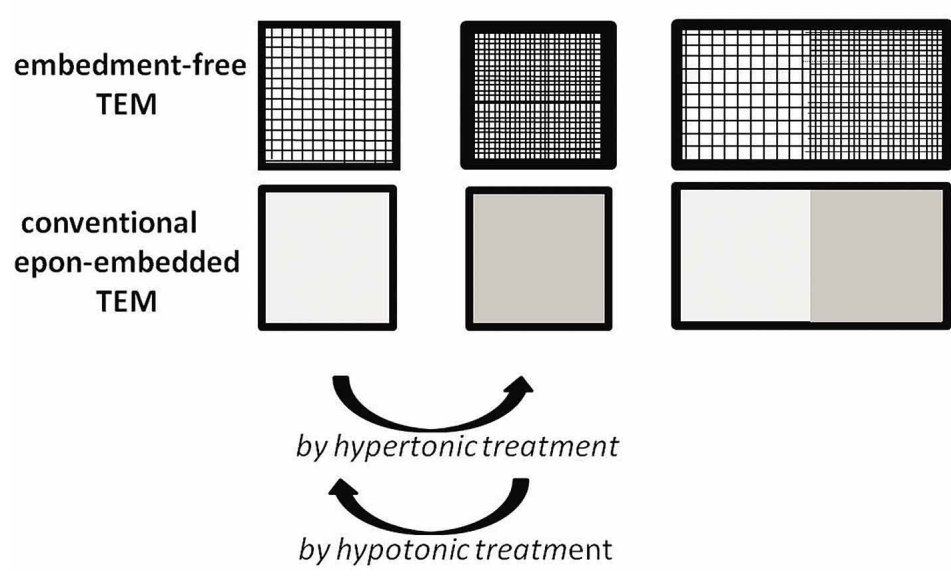

Fig. 2. Schematic drawings of three types of cells represented by rectangles with thick lines: the first (a), with cytoplasmic matrix of low electron density in conventional TEM and that of loose lattices in embedmentfree section TEM, the second cell (b), with cytoplasmic matrix of high electron density in conventional TEM and that of compact lattices in embedment-free section TEM; and the third (c), with cytoplasmic matrix of low electron density/loose lattices and that of high electron density/ compact lattices in contiguity with each other without any membranous partitions. The first is interpreted to contain cytoplasmic proteins at lower concentrations and the second to contain those at higher concentrations, while the third is interpreted to contain cyplasmic matrix of both solated and gelated states in contiguity with each other. In addition, the first cell and the second cell may change to each other by hypertonic and hypotonic treatments as indicated by arrows.
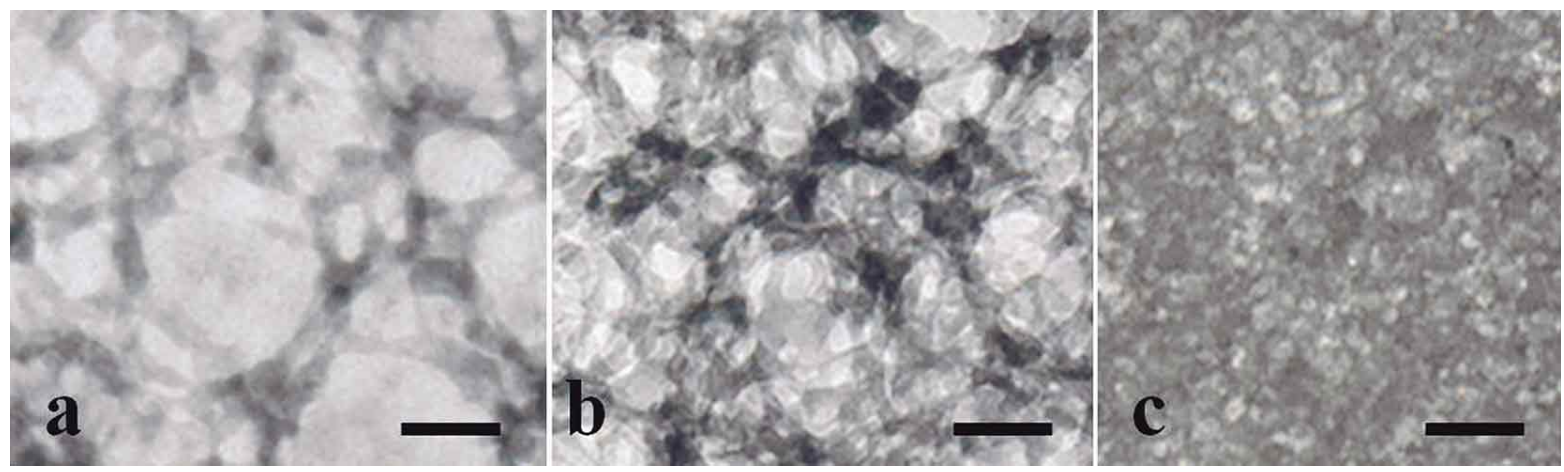

Fig. 3. Ultrastructures of bovine serum albumins (BSAs) at $8 \%$ (a), $10 \%$ (b) and $30 \%$ (c) as prepared in embedment-free section TEM. Note appearance of more compact lattices at increasing concentrations of proteins. Bars represents $100 \mathrm{~nm}$. 


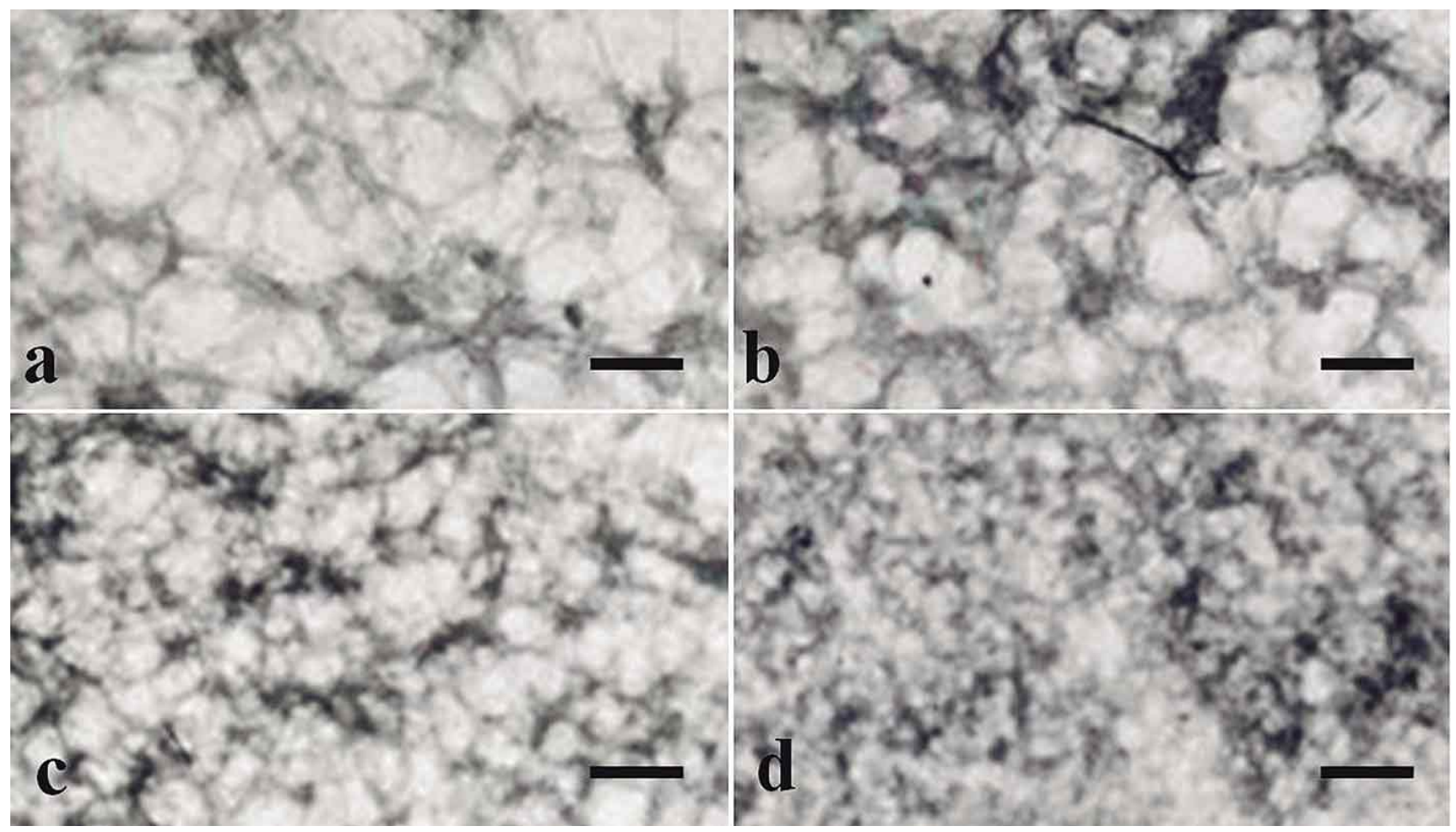

Fig. 4. Ultrastructures of gelatins at $8 \%(\mathrm{a}$ and b) and $10 \%$ (c) concentrations which are fixed at a warm temperature (solated state), and ultrastructures of those at $8 \%$ (c) and $10 \%$ (d) fixed at a cold temperature (gelated state) in embedment-free section TEM. Note that difference in the lattice-compactness between warm gelatins at $8 \%$ and $10 \%$ is similar to that between BSAs at the same concentrations, while cold gelatins exhibit more compact lattices than warm gelatins at the same concentrations. Bars represent $100 \mathrm{~nm}$.

Based on the findings from the in vitro experiment summarized above, a new interpretation on cell ultrastructures in the embedment-free section TEM is proposed (Kondo, 2010): First, differences in the compactness of cytoplasmic lattices represent those in the protein concentration in the cytoplasmic matrix; second, when loose and compact lattices are contiguous without any membranous compartmentations in a given cell, a cytoplasmic matrix domain occupied by the compact lattice is at a gel state, while remaining domains of the same cell at a sol state (Fig. 2c).

Since the sol-to-gel transition can occur as a reversible change in the consistency of a protein, it is possible that a given cell or cell domain is of sol at a time and gel at the other time depending on some circumstances. Therefore, it is crucial to find cases to which this interpretation on the strand-lattice and its compactness in the embedment-free section TEM in view of the sol/gel transition could be applicable. One of plausible examples is the cytoplasmic matrix in Nissl's domain exhibiting compact lattices, which is in a gelated state while the remainder exhibiting relatively loose lattices is in a solated state (Fig. 5). Another is the change in the lattice compactness under experimental hypersecretion of the neurohypophyseal axon terminals which secrete oxytocin and vasopressin. Under hyper-secretion by artificial dehydration (stop of water supply for one day), ultrastructural profiles of the axon terminals occupied by more compact lattices of strands were encountered in random sections much more frequently than under normal condition in the neurohypophysis in the embedment-free section TEM (please refer to Figs. 8a \& 8b in Kondo, 2010). This change seems to be similar to that in aggregated erythropore reported by others (Luby \& Porter, 1980). It remains to be elucidated whether or not the exocytosis of the secretory granules may induce, or result from, the sol to gel phase transition in the cytoplasmic matrix of the axon terminals.

\section{CONCLUSION}

If the proposed interpretation on the cytoplasmic matrix in this study is confirmed to be correct by further related studies in physics and chemistry, it will be possible to understand the dynamic properties of the cell not only by the cytoskeleton but also by the sol/gel states of cytosolic proteins and their concentration in distinct association with cellular ultrastructural entities. The same essentially holds true for the nucleoplasm and the intranuclear dynamics (Nalepa \& Harper, 2004; Nickerson, 2001). This would be a resurrection of the cytological sol/gel (Kondo, 2010, 2015). 
HIPKAEO, W. \& KONDO, H. New and probable ultrastructural criteria for identification of cytoplasmic sol- and gel-states. Int. J. Morphol., 34(1):212-217, 2016.
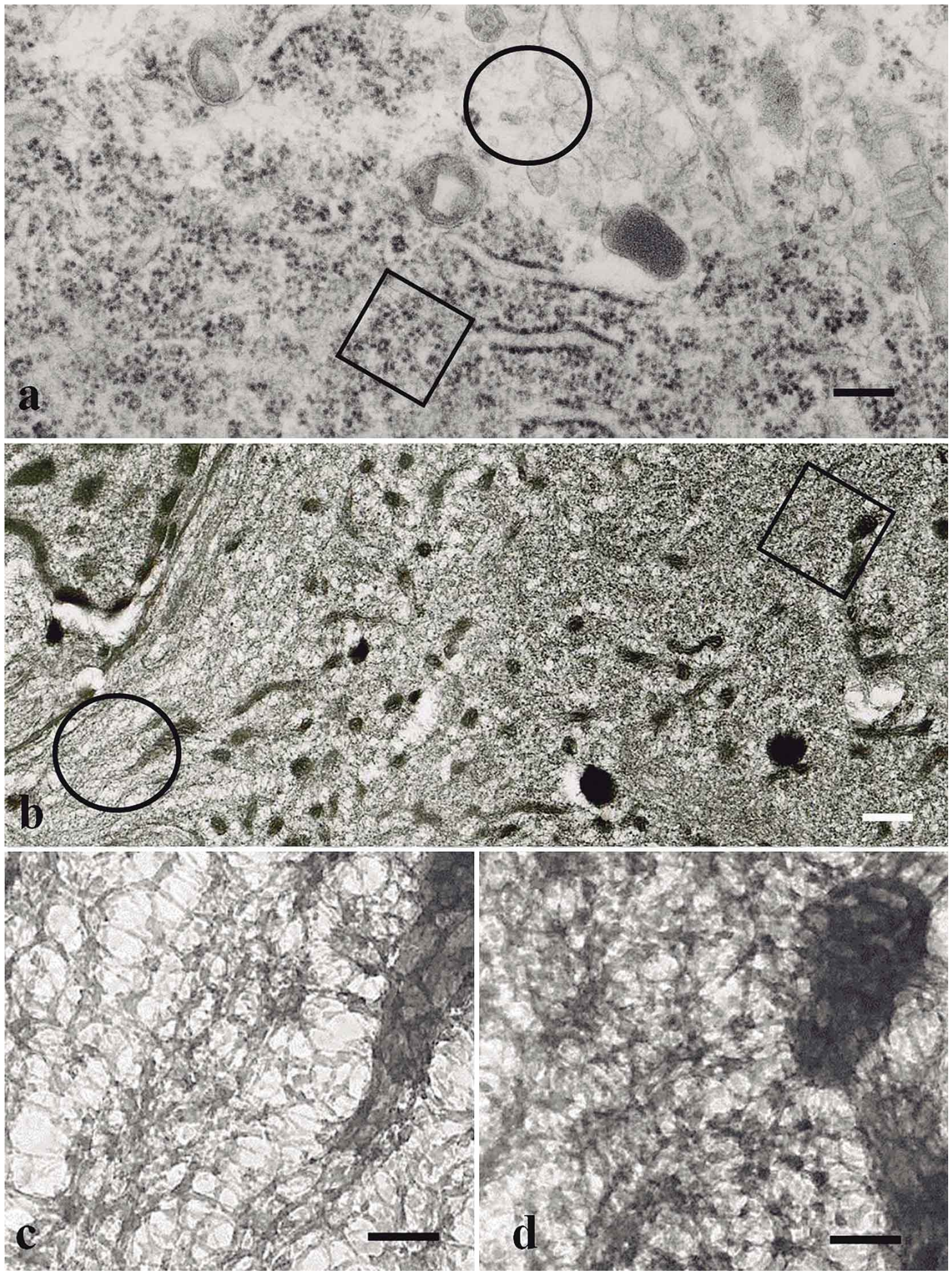

Fig. 5. Ultrastructures of neuronal perikaryal cytoplasm in conventional TEM (a), and embedment-free section TEM (b). Note cytoplasmic matrices with light electron density (enclosed by circle) and high electron density (enclosed by rectangle) in 5a. Ultrastructures at higher magnification (c and d) of cytoplasmic domains enclosed by circle (c) and rectangle (d) in 5b. As shown schematically in Fig 2, it is possible to state that cytoplasmic domain shown in $5 \mathrm{c}$ (corresponding to encircled area in 5a) represents a solated state, and that in $5 \mathrm{~d}$ (corresponding to that enclosed by rectangle) represents a gelated state. Bars represent $100 \mathrm{~nm}(5 \mathrm{a}, 5 \mathrm{c}, 5 \mathrm{~d})), 500 \mathrm{~nm}(5 \mathrm{~b})$. 
HIPKAEO, W. \& KONDO, H. Nuevo y probable criterio ultraestructural para la identificación de los estados citoplasmáticos sol - gel. Int. J. Morphol., 34(1):212-217, 2016.

RESUMEN: En microscopía electrónica de transmisión, la inclusión-libre sin el uso de medios de inclusión epoxi, la matriz citoplasmática (los orgánulos celulares y elementos, incluyendo los citoesqueletos) se mantienen en su lugar y las redes de hebras aparecen claramente y constantemente en cada célula. Su tamaño compacto es variable en diferentes tipos de células y en diferentes dominios de una y la misma célula, y es modificable bajo hipo o hiper-osmolaridad. Además, la aparición de redes de hebras es duplicable en las proteínas artificiales en diferentes estados de concentraciones sol / gel. En este contexto se ha propuesto un criterio ultraestructural nuevo y probable para la identificación de los estados sol / gel citoplasmáticos, con el objetivo de que las propiedades dinámicas de la célula se comprendan no solo a partir del citoesqueleto, sino también a partir de los estados sol / gel de proteínas citosólicas y su concentración en relación con una asociación indistinta con las entidades celulares ultraestructurales.

PALABRAS CLAVE: Sol / gel; Citoplasma; Inclusión libre; Ultraestructura.

\section{REFERENCES}

Buchsbaum, R.; Buchsbaum, M.; Pearse, J. \& Pearse, V. Animals Without Backbones. $3^{\text {rd }}$ ed. Chicago, University of Chicago Press, 1987.

Chambers, R. \& Chambers, E. L. Explorations Into the Nature of the Living Cell. Cambridge, Harvard University Press, 1961.

Crick, F. H. C. \& Hughes, A. F. W. The physical properties of cytoplasm: A study by means of the magnetic particle method Part I. Experimental. Exp. Cell Res., 1(1):37-80, 1950.

Flory, P. J. Principles of Polymer Chemistry. Ithaca, Cornell University Press, 1953.

Kondo, H. Reexamination of the reality or artifacts of the microtrabeculae. J. Ultrastruct. Res., 87(2):124-35, 1984a.

Kondo, H. Polyethylene glycol (PEG) embedding and subsequent deembedding as a method for the structural and immunocytochemical examination of biological specimens by electron microscopy. $J$. Electron Microsc. Tech., 1(3):227-41, 1984b.

Kondo, H. Embedment-free section electron microscopy. J. Electron Microsc. (Tokyo), 55(4):231-43, 2006.

Kondo, H. What we have learned and will learn from cell ultrastructure in embedment-free section electron microscopy. Microsc. Res. Tech., 71(6):418-42, 2008.

Kondo, H. Ultrastructural consideration on the nature, sol and gel, of the aqueous cytoplasm in embedment-free section electron microscopy. Adv. Colloid Interface Sci., 160(1-2):49-55, 2010.

Kondo, H. Ultrastructure of cytoplasmic matrix. J. Intergr. Creative Stud., l(1):1-19, 2015

Kondo, H.; Wolosewick, J. J. \& Pappas, G. D. The microtrabecular lattice of the adrenal medulla revealed by polyethylene glycol embedding and stereo electron microscopy. J. Neurosci., 2(1):57-65, 1982.

Kuhn, W.; Peterli, E. \& Majer, H. Freezing point depression of gels produced by high polymer network. J. Polym. Sci., 16(82):539-48, 1955.

Landau, J. V.; Zimmerman, A. M. \& Marsland, D. A. Temperature-pressure experiments on amoeba proteus; plasmagel structure in relation to form and movement. J. Cell. Physiol., 44(2):211-32, 1954.
Lechene, C. Cellular volume and cytoplasmic gel. Biol. Cell, 55(3):17780, 1985.

Luby, K. J. \& Porter, K. R. The control of pigment migration in isolated erythrophores of Holocentrus ascensionis (Osbeck). I. Energy requirements. Cell, 21(1):13-23, 1980.

Nalepa, G. \& Harper, J. W. Visualization of a highly organized intranuclear network of filaments in living mammalian cells. Cell Motil. Cytoskeleton, 59(2):94-108, 2004

Nickerson, J. A. Experimental observations of a nuclear matrix. J. Cell Sci., 114(Pt. 3):463-74, 2001

Pollack, G. H. Cells, Gels and the Engines of Life. Seattle (WA), Ebner and Sons Publishing, 2001.

Porter, K. R. The cytomatrix: a short history of its study. J. Cell Biol., 99(1 Pt. 2):3s-12s, 1984.

Tanaka, T. Gels. Sci. Am., 244(1):124-36, 138, 1981.

Taylor, D. L. \& Condeelis, J. S. Cytoplasmic structure and contractility in amoeboid cells. Int. Rev. Cytol., 56:57-144, 1979.

Tohyama, K. \& Miller, W. G. Network structure in gels of rod-like polypeptides. Nature, 289(5800):813-4, 1981.

Wolosewick, J. J. The application of polyethylene glycol (PEG) to electron microscopy. J. Cell Biol., 86(2):675-81, 1980.

Wolosewick, J. J. \& Porter, K. R. Microtrabecular lattice of the cytoplasmic ground substance. Artifact or reality. J. Cell Biol., 82(1):114-39, 1979.

\section{Correspondence to: \\ Wiphawi Hipkaeo \\ Anatomy Faculty of Medicine \\ Khon Kaen University \\ Khon Kaen, 40002 \\ THAILAND}

Email:Wiphawi@kku.ac.th

Received: 05-10-2015

Accepted: 06-11-2015 